\title{
Attitudes of Secondary School Students in Jordan Toward Contemporary Educational Concepts
}

\author{
Nibal Abdelkarim Mousa Malkawi ${ }^{1}$ \\ ${ }^{1}$ Al Balqa Applied University, Salt, Jordan \\ Correspondence: Nibal Abdelkarim Mousa Malkawi, Al Balqa Applied University, Salt, Jordan. E-mail: \\ nibal_malkawi@yahoo.com
}

Received: December 3, 2019

Accepted: January 8, 2020 Online Published: January 14, 2020

doi:10.5539/jel.v9n1p229

URL: https://doi.org/10.5539/jel.v9n1p229

\begin{abstract}
This study aimed to identify the degree of awareness of secondary school students in public schools in Jordan of modern educational concepts and the extent of their representation. The sample of the study consisted of 920 male and female students, a questionnaire consisted of 54 items was distributed among them, it was consisted of six domains, according to independent variables which are: gender, specialization, region, where the dependent variable was the degree of awareness of secondary school students of modern educational concepts.

The results showed that the relative importance of the domains in the total score was $72.14 \%$ when the domains obtained the following: the concept of integrated personality $(73.36 \%)$, education for life and work $(70.10 \%)$, responsibility $(74.35 \%)$, continuous education $(72.42 \%)$, rationality and critical thinking $(72.38 \%)$, and the concept of democracy in the field of education $(70.30 \%)$, the effect of the gender variable in favor of males has been shown in the total degree and on all fields of study, as well as the scientific specialization in all areas and the total degree, differences have appeared in favor of urban students in the total degree and for the benefit of rural students in the areas: building an integrated personality, and take responsibility and democratic education.
\end{abstract}

Keywords: contemporary educational concepts, integrated personality, responsibility, continuous education, rationality and critical thinking

\section{Introduction}

As societies, including Arab societies, enter the 21st century, despite keeping abreast of this age with all its techniques and developments, and its serious and diligent attempt to invest in all available fields, however, the education sector still needs more effort and support for the education profession as the most sacred profession among others, because it is not only concerned with building the minds of learners, but also to develop their attitudes, beliefs and abilities, and to meet their needs, tendencies and interests, this means taking care of their integrated personality (Turki et al., 1996)

The professionalism of the education profession in many societies, including Arab society, Still tainted by some misunderstanding and lack of appreciation, the presence of large numbers of incompetent teachers,, as well as the deterioration of material conditions, the social conditions of the teaching profession, and the multiplicity of responsibilities assigned to teachers and their multiplicity, all contributed greatly, in the lack of demand for the profession, and reluctance, which affect the education sector, as a result of the unsatisfactory reality of the status of teachers and their profession in our Arab society, as grumbling from teachers, their poor choice, the shallowness of their culture, and the lack of sufficient training to enable them to keep up with the times and new technologies, have become a manifestation of general weakness (Which has become the status of the Arab teacher in recent years) (Janini, 1995).

Teacher preparation is a subject that can be developed and changed. This has led many educators to submit perceptions and proposals that have had a clear impact on the development of teacher training programs. These programs have moved from one philosophy to another in order to achieve the best possible educational vision for the teacher preparation process. Whereas the classes of the first basic cycle of the basic education stage are the main pillar on which the following is built, in the educational process to which the student is subjected, educators have paid special attention to the teacher of this stage (Kentch, 2001), where the faculties of education in most of the world, which seeks to develop the outputs of public education, which focuses on the first 
childhood as a key pillar in building society, and to develop programs for the preparation of teachers of first grades, recognizing the importance of this Stage in community development, steadily enter the world of global competition, and develop the potential available, to maximize the benefit of young people.

The growing global interest in in-service teacher preparation programs, most educators and those interested in this field should strive to reconsider the methods of preparing this category of teachers, and this is done through careful planning of their preparation programs, in the light of the facts of reality, and what they aspire to achieve through future education plans and programs (Hamasha, 2000). Plans for the development of first-grade teacher training programs should be based on constants that are relevant to the reality of teachers on the one hand and to the needs of the community on the other, taking into account the potential and resources available to the educational institution (Scott \& Mior, 2000).

In general, teacher development plans should take into account reality, and starting from it, based on the constants and facts that require development and not just in response to global theories may not relate to reality, at present, faculties of education and teacher training institutions in general face many new global challenges, which are more dangerous, deeper and more urgent than those faced by society in the twentieth century; therefore, these challenges must be addressed through Attention to the development of faculties of education programs and teacher training plans at the national level (Ministry of Education Publications, 2004); as the fast changes experienced by contemporary society, and the resulting challenges, have produced a set of contemporary educational concepts that have become real targets of modern educational systems. Seek to represent and work to achieve them. Arisen the need for democratic education because of the spread of democratic thought, education is closely linked to democracy, because of their great importance, by providing opportunities for education for all, developing the individual's personal abilities as much as possible, and acquiring many knowledge and skills, the values of good citizenship, and contemporary trends, by providing opportunities for social integration, through the dissemination of the principles of freedom, justice and equality, and entrenched among members of society, and practice with young people, thought and behavior (Watfa \& Shehab, 2004).

Educational thought also showed great interest in how to use the knowledge of individual differences, in order to have an effective impact in the educational process, and stressed that the teacher to know what each individual has many abilities not yet used (Barrett, 2000).

This necessitated that the teacher be kept abreast of what is happening in the field of educational technology, and choose methods that suit the educational situation, and the characteristics of his students and to innovate others, so as to provide opportunities for students to learn how to learn, so that they can use the knowledge and skills acquired in working situations (Abu Halawa, 1996). The school plays a key role in instilling students' continuing education trends; it strengthens their desire to continue learning after reaching a certain stage, because the primary goal of education is to produce learners who are responsible for creating and managing their learning within and outside the school (UNESCO, 1972).

It is linked to the idea of continuous education, the idea of integration in education, training and preparation where integrated education becomes an imperative to keep pace with the requirements of this era, by making self-learning a central axis to organize the practical experiences contained in the curriculum, so as to ensure the teacher and learner continuous education and integrated growth, and this requires achieving balance Between the theoretical and practical aspects, and to emphasize the elements of professional growth based on self-activity (Aduwa, 2005). It is worth mentioning that creative education is required and does not occur in a vacuum, but must be taken within the framework of a holistic view of the role of family and community institutions, and prevailing educational, economic, cultural and cultural influences, and the education of the individual cannot take place in isolation from his social and natural environment. Contemporary education requires a creative teacher to have a strong personality and self-confidence, a weak teacher will often find himself vulnerable to criticism from students, parents and fellow teachers who have a great deal of self-confidence and a sense of personal value, and this will be reflected in his/her students, so a successful teacher trusts himself and instills confidence in his students (Jarwan, 1995).

The need to pay attention to environmental education in different stages of education in order to prepare a human being who understands his environment and aware of its circumstances is able to contribute positively to overcome its problems and dangers, to better improve the conditions of this environment, and to do so willingly and voluntarily (Demerdash, 1994), and if education is the golden key to progress, and the real gateway to tomorrow's world, with all its wishes, aspirations and challenges, and it is a tool of society to achieve the adaptation of new generations, the teacher is the mediator capable of achieving the goals of the school, and it is 
the school's first means of teaching young people, and the teacher is based on the implementation of these goals and translated into reality, and hence the current age needs the services of the teacher more than ever.

\subsection{Study Problem and Questions}

There are no Arab studies dealing with the six concepts of modern education addressed in this study: building an integrated personality, life and work, responsibility, continuous learning, critical thinking and democratic education, thus, the researcher's feeling was to conduct a field study on the degree of awareness of students of public secondary schools in Jordan of modern educational concepts and the extent of their representation. The interest in these concepts in our current education helps the young generation to overcome the challenges of the era. The study of this problem should contribute to the understanding of these modern concepts in education and represent and explain the practices associated with them on the reality. Therefore, from this perspective, the problem of the study will be determined by the following central question: What is the degree of awareness of secondary school students in public schools in Jordan of modern educational concepts and the extent to which they represent them?

This question is subdivided into the following sub-questions:

1) What is the degree to which students are influenced by educational concepts: building an integrated personality, life and work, responsibility, continuous learning, critical thinking, and democratic education, and what does this have to do with the sex of students?

2) What is the impact of secondary school students on these concepts and the degree of their representation according to specialization (scientific, literary)?

3) What is the degree to which secondary school students are affected by these concepts according to their area of residence (city, rural)?

4) What is the degree to which students are affected by these concepts according to the interaction of gender, specialization and region?

\subsection{Significance of the Study}

The importance of this study appears in the following:

1) Identify the reality of the awareness of secondary school students in public secondary schools of modern educational concepts and the degree of their representation.

2) Identify the differences in the awareness of the students of the official secondary stage of modern educational concepts and the extent of their representation, and can be attributed to the gender variable.

3) Identify the differences in the degree of awareness of these students of educational concepts and represent them, and can be attributed to variable Specialization.

4) Identify the differences in the degree of awareness of the students of the official secondary stage of modern educational concepts and their representation, due to the variable region in which they live.

\subsection{Study Limits}

- The study was limited to the stage of formal secondary education.

- The study sample included students (male, female) in both rural and urban areas.

- The study was limited to students of public schools in the scientific and literary specialization only.

\subsection{Study Variables}

The independent study variables were identified as follows:

- $\quad$ Sex variable (Male, female).

- Specialization variable (scientific, literary).

- Variable residential area (city, countryside).

The dependent variable is the degree of awareness of students of modern concepts in education and the extent of their representation.

\subsection{Definition of Terms}

\subsubsection{Modern Education}

It is intended for new education and is represented in the new educational principles that call for changing the traditional framework of the school. Teacher, learner and classroom framework, using educational technology, 
and self-learning methods throughout the entire life cycle, and depends on the individual differences of the learner and interests and needs and education is part of general education.

\subsubsection{Self-Assurance}

It is a concept of modern education that focuses on independence in thinking and criticism through dialogue, self-reliance, freedom of choice and responsibility.

\subsubsection{Integrated Personality}

It means open personality from all aspects of mental, psychological, emotional and physical.

\subsubsection{Continuous Education}

It is intended to learn the moment of birth and build expertise and constantly renewed.

\subsubsection{Rationality}

They rely on the mind and trust it and link between means and ends, and focus on useful experiences, and the development of scientific methods of thinking, and open mind in receiving new ideas, and the accuracy of information and careful in judging.

\section{Previous Studies}

Hamdan (2006) conducted a study aimed at identifying the degree of representation of teachers of higher government primary schools (tenth grade) of modern educational concepts, the descriptive method was used and the study population consisted of 450 teachers, the results of the study showed that the concepts addressed in the study were of moderate importance, it also pointed to the existence of statistically significant differences in the degree of teachers' representation of modern educational concepts.

Roney (2008) conducted a study aimed at identifying the characteristics of effective middle school teachers, from the point of view: principals, teachers, and students (case study), 32 participants were interviewed, where the results showed that the most prominent characteristics were flexibility, adaptation, kindness, enthusiasm, class management, communication skills, patience, honesty and creativity.

Al-Amawi (2003) conducted a study aimed at revealing the reality of educational technologies in primary schools in Irbid 1st Directorate of Education. The sample of the study consisted of 662 teachers and it was chosen using the random method, and a questionnaire was developed included the degree of availability of materials, and the degree of their use, where the results highlighted the existence of statistically significant differences in the use of educational materials and devices, attributed to the gender variable, training courses, expertise and academic specialization in favor of females, the study also pointed to the existence of a set of constraints that reduce the use of teaching aids, including those related to management and those related to the teacher or the teaching medium itself.

Al-Katout (2003) conducted a study aimed at comparing equal educational opportunities in Islam and contemporary educational thought, the researcher used the descriptive analytical method based on comparison, where the results of the study revealed the existence of equal educational opportunities in the two ideas represented in continuous education. Compulsory education and advocacy for the elimination of illiteracy problems, and the girls' right in education, in addition to the multiplicity and diversity of educational institutions, the study also showed that the principle of equal educational opportunities in Islam stems from the principle of justice and equality, while in contemporary educational thought was a natural result of human thought.

The study of Abu Latifa and Assaf (2008) aimed at revealing the level of confidence of students of practical education in Jordanian universities to work as teachers, a sample of 217 students was selected in a simple random manner, from the students of practical education enrolled in the practical education program in 2008 and to collect/first semester 2007 data, the researchers built a questionnaire (tool) consisting of 60 paragraphs, the study found that the confidence level of students of practical education in Jordanian universities themselves, as teachers, was high. The results of the study also showed that there are statistical differences between the mean levels of confidence attributed to the university variable.

\section{Methodology}

\subsection{Population of the Study and Its Sample}

The study population consisted of high school students (scientific and literary) in public schools in Jordan, and the number of 900507 male and female students distributed in all governorates of the Kingdom. A sample of 920 male and female students was selected from the community in a simple and random manner from the first and second grades secondary male and female. The researcher chose selected secondary schools for males and 
females in northern, central and southern Jordan and chose by random drawing 460 students from male schools interviewed by 460 students from female schools.

\subsection{Tools of the Study}

Before starting the design of the study tool, the researcher reviewed what was written in this field of international studies, and books in the fields of education and psychology.

A) The design of the study questionnaire, which contains 54 items divided into six domains: the concept of integrated personality, education for life and work, responsibility, continuous education, rationality and critical thinking, and the concept of democracy in the field of education. Each item included the selection of a grade of five degrees according to the degrees of Likert scale: highly agree, agree, hesitant, disagree, never agree, and were given the following scores for the previous paragraphs respectively $(1,2,3,45)$.

B) Interviews: Before distributing the questionnaire, the researcher interviewed the sample to clarify some items and respond to queries. He also collected some observations that helped him to explain his findings.

\subsection{Validity and Reliability of the Tool}

The validity of the tool was verified by presenting it to a committee of arbitrators and specialists, which consisted of 10 arbitrators from the faculty members of Al-Balqa Applied University and the Hashemite University, as well as offering it to specialists in the Ministry of Education, in order to judge the extent of the items belonging to the fields, as well as to judge the degree of suitability of the item in terms of formulating structurally and linguistically. After adopting the opinions of the arbitrators, the unanimous items were chosen, and the items that they proposed were amended, and reformulated. The number of paragraphs in their final form became 54 items instead of 60 items, after 6 paragraphs were deleted and 6 fields are: the concept of integrated personality, education for life and work, responsibility, continuous education, rationality and critical thinking, and the concept of democracy in the field of education.

The reliability of the questionnaire was calculated on the study population of 920 male and female students using the Test-retest method. The reliability coefficient for the questionnaire of students' attitudes towards contemporary educational concepts was 81.0, which is one of the accepted values for the purposes of the study, and the Alpha Cronbach test was used to test the degree of compatibility of respondents with the questionnaire items, as it reached 87.7 .

\subsection{Statistical Treatment}

Data were treated using the principles of statistics in order to find arithmetic averages, percentages of fields of study and standard deviations. Three-way Analysis of variance was also used to investigate the effect of the variable sex, specialization, region, and interaction between them on the fields of study and overall score.

\section{Results of the Study}

The study reached the following results:

With regard to the answer to the central question, "What is the degree of awareness of secondary school students in public schools in Jordan to modern educational concepts and how they represent them in terms of their relative importance?" Table 1 shows this:

Table 1. The relative importance of the fields of study in the total degree

\begin{tabular}{lll}
\hline Study domains & Mean & Standard deviation \\
\hline Build an integrated personality & 73.36 & 12.5470 \\
Life and work & 70.10 & 13.0065 \\
Take responsibility & 74.35 & 14.693 \\
Continuous education & 72.42 & 14.411 \\
Critical thinking & 72.38 & 13.139 \\
Democratic Educatio & 70.30 & 16.578 \\
Total score & $\mathbf{7 2 . 1 4}$ & $\mathbf{1 0 . 9 9 4}$ \\
\hline
\end{tabular}

The above table with regard to the degree of each domain of study indicated that the area of responsibility and the degree of representation of students received the highest degree, followed by the domain of building an integrated personality, then the domains of continuous education and critical thinking, while the concept of democratic education and education for life and work received the lowest proportions, which requires a focus in 
their development. Overall, the degree of awareness of male and female students and the degree of their representation of modern and contemporary educational concepts in the total degree has reached 72.14 which is a significant proportion and much higher than the average. This result is consistent with the results of Al-Katout (2003) study.

As for the answer to the first question, which is subdivided from the central question: "What is the degree to which students are influenced by educational concepts: building an integrated personality, life and work, responsibility, continuous learning, critical thinking, democratic education, and what does this have to do with the sex of students?" Table 2 illustrates this:

Table 2. Arithmetic averages and standard deviations of the effect of gender variable

\begin{tabular}{lllllll}
\hline Domains & Mean & $\mathbf{N}$ & Standard deviation & Mean & $\mathbf{N}$ & Standard deviation \\
\hline Build an integrated personality & 75.2 & 460 & 11.3 & 71.8 & 460 & 13.7 \\
Life and work & 70.5 & 460 & 12.5 & 69.9 & 460 & 13.7 \\
Take responsibility & 75.1 & 460 & 14.2 & 73.8 & 460 & 15.3 \\
Continuous education & 72.5 & 460 & 14.6 & 72.5 & 460 & 14.4 \\
Critical thinking & 72.1 & 460 & 13.5 & 73.1 & 460 & 12.9 \\
Democratic Education & 69.3 & 460 & 16.6 & 71.5 & 460 & 16.7 \\
Total score & $\mathbf{7 2 . 4}$ & $\mathbf{4 6 0}$ & $\mathbf{1 0 . 6}$ & $\mathbf{7 2 . 1}$ & $\mathbf{4 6 0}$ & $\mathbf{1 1 . 6}$ \\
\hline
\end{tabular}

The above table shows the appearance of gender differences in favor of male students in the total degree, and in all areas of study, except the field of critical thinking, the proportion was higher in favor of female students. This result agreed with the results of Al-Amawi (2003) which shows an effect of gender variable.

With regard to the answer to the second sub-question, which is: "What is the degree to which secondary school students are affected by these concepts and represent them according to specialization (scientific, literary)?" The following table shows:

Table 3. Arithmetic averages and standard deviations for the effect of variable of specialization (scientific, literary)

\begin{tabular}{lllllll}
\hline Domains & Mean & $\mathbf{N}$ & Standard deviation & Mean & N & Standard deviation \\
\hline Build an integrated personality & 73.9 & 464 & 12.1 & 73 & 464 & 13 \\
Life and work & 71.6 & 464 & 11 & 68.7 & 464 & 14.7 \\
Take responsibility & 76.1 & 464 & 13.2 & 73 & 464 & 15.9 \\
Continuous education & 74.1 & 464 & 13.5 & 68.7 & 464 & 15.2 \\
Critical thinking & 74.5 & 464 & 11.9 & 73 & 464 & 14 \\
Democratic Education & 71.8 & 464 & 14.2 & 68.7 & 464 & 18.6 \\
Total score & 73.6 & 464 & 9.6 & 73 & 464 & 12.1 \\
\hline
\end{tabular}

The above table shows the emergence of differences in favor of the scientific specialization variable in the total degree and in all domains. This result also agreed with the results of Abu Latifa and Assaf (2008), and Al-Amawi (2003) which shows an effect specialization.

With regard to the answer to the third question, which is: "What is the degree to which secondary school students are affected by modern educational concepts according to their area of residence (two cities)?" The following table shows:

Table 4. Arithmetic averages and standard deviations of the effect of the region variable (city, rural)

\begin{tabular}{lllllll}
\hline Domains & City & & & \multicolumn{2}{l}{ Rural } \\
\hline Build an integrated personality & Mean & N & Standard deviation & Mean & N & Standard deviation \\
Life and work & 72.8 & 474 & 12.1 & 74 & 446 & 12.9 \\
Take responsibility & 71.5 & 474 & 12.4 & 69.1 & 446 & 13.5 \\
Continuous education & 74.1 & 474 & 15 & 74.7 & 446 & 14.4 \\
Critical thinking & 73.1 & 474 & 13.8 & 72 & 446 & 15 \\
Democratic Education & 72.5 & 474 & 13.2 & 72.3 & 446 & 13.1 \\
Total score & 70.1 & 474 & 16.6 & 70.7 & 446 & 16.6 \\
Build an integrated personality & 72.5 & 474 & 10.7 & 72.1 & 446 & 11.3 \\
\hline
\end{tabular}


In the previous table, there were differences in favor of the city in the overall degree, but differences appeared in favor of rural students in the domain of building integrated personality, responsibility, and democratic education, more than urban students.

To answer the fourth and final question of the study, which is: "What is the degree to which students are affected by these previous concepts according to the interaction of gender, specialization and region in the total degree?"

Table 5. The effect of the interaction of gender, specialization and region

\begin{tabular}{llllll}
\hline Source of variance & Sum of squares & Df & Mean of squares & "F" value & Sig \\
\hline Gender & 4.527 & 1 & 4.527 & 0.39 & 0.845 \\
Specialization & 786.714 & 1 & 786.714 & 6.692 & 0.010 \\
Region & 5.201 & 1 & 5.201 & 0.044 & 0.833 \\
Gender + specialization & 298.110 & 1 & 298.110 & 2.536 & 0.112 \\
Gender + region & 510.616 & 1 & 510.616 & 4.344 & 0.318 \\
Specialization + region & 71.971 & 1 & 71.971 & 0.621 & 0.434 \\
Gender, specialization and region & 672.424 & 1 & 672.424 & 5.720 & 0.017 \\
Total & 55600.907 & 459 & & & \\
\hline
\end{tabular}

Table 5 shows the effect of the specialization in the total degree in favor of the scientific specialization, it also shows the effect of the interaction between the gender variable and the area of residence was also shown in favor of male students, it was for rural students, while for female students for urban students.

The table also shows the impact of the interaction between gender, specialization and area of residence. The highest averages for male students were from the literary specialization in the countryside, while the lowest was for females in the literary branch in the countryside.

\section{Recommendations}

- $\quad$ Attention to the system of educational concepts and values contained in the study tool and work to develop them among students.

- The study stresses the importance of the role of schools in building a system of educational and cultural concepts and values for members of society.

- $\quad$ Conducting more studies on other educational concepts and values, and with different samples.

\section{References}

Abu, H. N. (1996). The effect of the gender of the classroom teacher and his scientific experience and scientific qualification in the use of techniques in teaching students of Zarqa Governorate. Unpublished Master Thesis, University of Jordan, Amman, Jordan.

Abu, L. R., \& Al-Assaf, J. (2008). The level of confidence of students of practical education in Jordanian universities themselves as teachers (pp. 195-215). Working Paper for the Conference of the Faculty of Educational Sciences (24-27) April, Zarqa Private University, Zarqa, Jordan.

Aduwa, S, (2005). Using information and communication technology in secondary school in Nigeria, problems. Educational Technology and Society, 8(1), 104-112.

Al-Amawi, A. (2003). The reality of the use of educational techniques in the primary schools in the Irbid region from the point of view of the teachers of these schools. Unpublished Master Thesis, Yarmouk University, Irbid, Jordan.

Al-Katout, O. (2003). Equal educational opportunities in Islam and contemporary educational thought. Unpublished PhD thesis, University of Jordan, Amman, Jordan.

Barrett, J, (2000). Test tour aptitude personality and motivation and plan your career. Kogan, London, UK.

Demerdash, S. (1994). Al-Falah Publishing and Distribution Library. Kuwait.

Hamasha, S. (2000). Administrative problems facing the first-grade teachers in Irbid schools. Unpublished Master Thesis, Yarmouk University, Irbid, Jordan.

Hamdan, N. (2006). A degree representing the teachers of the higher government primary schools (tenth grade) in Zarqa Governorate for the selected modern educational concepts and the attitudes of students towards them. 
Janini, N. (1995). Social challenges and education of the Arab teacher for the twenty-first century. A working paper presented at the Conference of Arab Teacher Education in the 21st Century, Amman.

Jarwan, F. (1995). Talent, excellence and creativity. University Book House, Al Ain.

Kentch, M. (2001). Philosophy of teacher preparation in light of contemporary challenges. Book Center for Publishing and Distribution, Egypt.

Ministry of Education. (2004). Ministry of Education Publications. Ministry of Education, Department of Teaching, Amman, Jordan.

Roney, K. (2008). Characteristics of effective middle level teachers, a case study of principle, teacher and student perspectives. Unpublished Doctoral dissertation, Temple University, Phi Adel phia, PA., Retrieved April, 17.

Scott, A. G., \& Freeman-Mior, J. (2000). Tomorrows, teacher international and critical perspective on teacher education. Canterbury University press, New Zealand.

Turki, N. et al., (1996). Analytical study of some educational policies for teacher preparation in Qatar. Journal of the College of Education, 1(2), 604-653.

UNESCO. (1972). The school and continuing education. Paris, United nation.

Watfa, A., \& Shehab, A. (2004). School sociology, Baynunah phenomenon and social function. University Foundation for Studies and Publishing, Beirut.

\section{Copyrights}

Copyright for this article is retained by the author, with first publication rights granted to the journal.

This is an open-access article distributed under the terms and conditions of the Creative Commons Attribution license (http://creativecommons.org/licenses/by/4.0/). 